\title{
A Criação do Centro de Atenção Psicossocial Espaço Vivo
}

The creation of the psychosocial attention center "living space"

\section{Sérgio Luiz Ribeiro}

Psicólogo pela Universidade Estadual Paulista (UNESP) de

Assis-SP.

Especialista em

Psicologia Clínica.

Psicólogo do CAPS

Espaço Vivo de Botucatu-SP. (de 1999 até 2002)

Psicólogo do Ambulatório Regional de Saúde Mental de Bauru-SP.

Professor do Curso de

Psicologia da Universidade Paulista -

UNIP de Bauru-SP. Mestrando

em Psicologia e Sociedade pela Unesp de Assis-SP

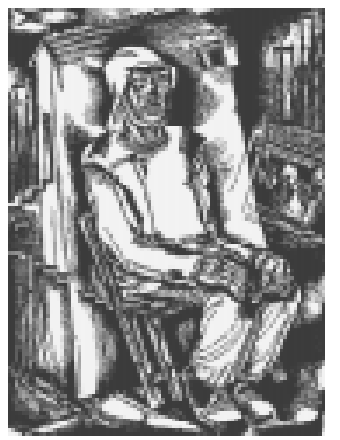

Resumo: Este artigo trata do processo da reforma psiquiátrica brasileira, a partir dos anos 80, que levou ao surgimento de serviços alternativos em saúde mental. Mais especificamente, aborda a criação e organização do Centro de Atenção Psicossocial Espaço Vivo, de Botucatu-SP, que ocorreu a partir das transformações no atendimento aos pacientes psicóticos do Hospital Professor Cantídio de Moura Campos. Faz reflexões sobre a importância do trabalho em equipe e do respeito à singularidade e subjetividade dos envolvidos nesse processo de mudança da forma de atendimento ao sofrimento mental.

Palavras-Chave: Centro de atenção psicossocial, saúde mental, serviços alternativos, equipe interdisciplinar, reforma psiquiátrica brasileira.

Abstract: This article deals with the process of the Brazilian psychiatric reform, since the 80 's, that led to the implementation of the alternative services in mental health. It discusses more specifically the creation and organization of the Psychosocial Attention Center "Living Space" of Botucatu-SP, Brazil. This was possible due to the transformations in the care of psychotic patients of "Professor Cantídio de Moura Campos" Hospital. It considers the importance of team work and the respect to the singularity and subjectiveness of the ones involved in the process of changing the attendance of mental suffering.

Key Words: Psychosocial attention center, mental health, alternative services, interdisciplinary team, Brazilian psychiatric reform.

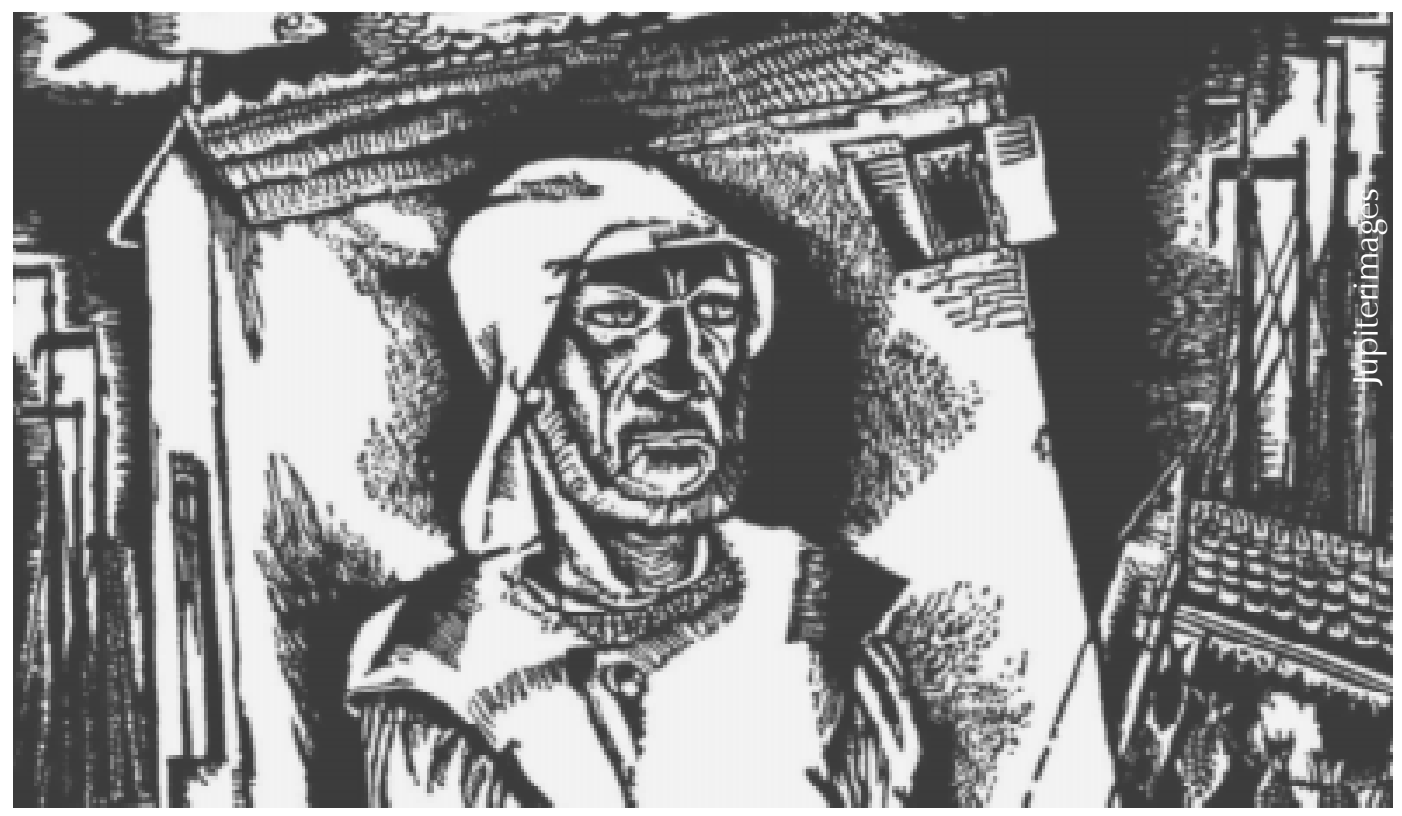

Este artigo pretende relatar o processo de criação do Centro de Atenção Psicossocial (CAPS) Espaço Vivo de Botucatu, cidade do interior paulista, de gestão pública estadual. Na primeira parte, será abordada a reforma psiquiátrica brasileira e as transformações ocorridas nas políticas de saúde mental que acabaram por levar à criação de serviços de saúde mental substitutivos às internações psiquiátricas e que Ihes serviram de inspiração. Depois, será narrado o processo de criação do
CAPS Espaço Vivo, do qual o autor foi participante, e sua inserção nesse processo de mudança na atenção à saúde mental.

Abordaremos a reforma psiquiátrica brasileira, especialmente a partir das décadas de 70 e 80, quando houve alterações mais substanciais na atenção à doença/saúde mental. Para um entendimento mais aprofundado das mudanças pelas quais passou a Psiquiatria desde seu início, 
seja no mundo seja no Brasil, sugerimos os trabalhos de Amarante (1998), Rezende (1987) e Tenório (2002).

\section{Reforma Psiquiátrica no Brasil}

Podemos sintetizar que, no Brasil, a atenção aos transtornos mentais inicia-se com a criação do Hospício Pedro II, no Rio de Janeiro, em 1852, que, até o final da $2^{a}$ Guerra Mundial, teve uma trajetória higienista. Esta surgiu, segundo Machado et al. (1987), como um projeto de medicalização do social, no qual a Psiquiatria aparece como um instrumento tecnocientífico de poder, em uma Medicina que se autodenomina social. A prática dessa atenção constitui-se num auxiliar da organização social e das cidades que surgiam, de controle político e social, segundo Birman (1978), uma Psiquiatria da higiene moral.

A partir do final da $2^{a}$ Guerra, principalmente na Inglaterra, França e Estados Unidos, mas também em outras partes do mundo, inclusive em países não ligados diretamente à guerra, surgem experiências socioterápicas no tratamento de transtornos mentais. Os hospitais psiquiátricos da época não estavam conseguindo cumprir sua função de recuperação dos pacientes. As causas eram a superlotação, a pequena quantidade de funcionários, a falência das propostas de tratamento existentes ou a própria ausência de qualquer proposta terapêutica. Somavam-se a tais fatores a necessidade de se recuperar um grande número de homens jovens que tiveram danos psicológicos com a guerra e a falta de mão-deobra para o trabalho. As experiências surgidas foram, principalmente, a comunidade terapêutica inglesa, a Psiquiatria de setor francesa e a Psiquiatria preventiva comunitária norte-americana. Estas acabaram por levar a Psiquiatria à construção de um novo objeto - a saúde mental, e não mais a doença mental.

Os objetivos da comunidade terapêutica eram a transformação do ambiente e do tratamento dos hospitais psiquiátricos pela "terapêutica ativa" ou terapia ocupacional. Esta foi criada por Hermann Simon, na década de 20: "a necessidade de mãode-obra para a construção de um hospital faz com que Simon lance mão de alguns pacientes considerados cronificados e observa efeitos benéficos em tal iniciativa" (Amarante, 1998, p. 28). Surge a crença e objetiva-se a reabilitação dos doentes mentais através do trabalho e da socialização por intermédio de atividades grupais e de maior participação dos pacientes em seu tratamento. $\mathrm{O}$ mais importante adepto dessa terapêutica foi Maxwell Jones, na Inglaterra, a partir de 1959.

A Psiquiatria de setor iniciou-se, na França, a partir de 1945, através de vários psiquiatras progressistas, principalmente Lucien Bonnafé. Tinha como objetivo estruturar um serviço público de ajuda e tratamento por meio da criação de equipes de atendimento multiprofissionais (psiquiatras, psicólogos, assistentes sociais e enfermeiros) que se responsabilizariam por uma determinada área geográfica, com a proposta de realizarem prevenção e tratamento das doenças mentais junto à comunidade, criando cuidados específicos segundo as demandas locais. Assim, a internação seria apenas uma etapa transitória no tratamento. A Psiquiatria de setor procurou romper com a estrutura alienante dos hospitais psiquiátricos, bem como evitar a segregação e o isolamento do doente. A partir de 1960, na França, foi incorporada como política oficial de saúde mental.

A Psiquiatria preventiva comunitária surge nos Estados Unidos, nos anos 70, originada do cruzamento da psiquiatria de setor e da comunidade terapêutica. Foi rapidamente adotada como política oficial de saúde mental naquele país e levou a um deslocamento da doença para a saúde mental no sentido de se combater tudo o que, na sociedade, pudesse interferir no bem-estar dos cidadãos. O preventivismo estava baseado nos estudos de Gerald Caplan e seu livro Princípios de Psiquiatria Preventiva (editado no Brasil, em 1980), onde havia a idéia de que os problemas de saúde e os problemas sociais seriam diminuídos ou até mesmo superados por intermédio da participação, da auto-ajuda e de oportunidades sociais. Aquele autor defendia a crença de que as doenças mentais podem ser prevenidas, se detectadas precocemente, e ressaltava que, se estas significam desvio e marginalidade, poder-se-ia, assim, prevenir e erradicar os males da sociedade por essa prevenção. Passa-se, enquanto objetivo maior, à identificação de pessoas potencialmente doentes, indo às ruas, às casas, para identificar aqueles que, por seu estilo de vida e hábitos, pudessem ser "suspeitos" de desenvolver doença mental e devessem ser conduzidos ao tratamento especializado. Essa forma de atenção à saúde mental foi adotada não só nos Estados Unidos, mas tornou-se referência para a América Latina, através da Organização dos Estados Americanos (OEA) e da Organização Mundial de Saúde (OMS), nas décadas de 70 e 80.

Em decorrência dessas alterações do período pósguerra, no Brasil, passou a coexistir a prática higienista com experiências inspiradas na Psiquiatria preventiva comunitária ou nas comunidades terapêuticas ou Psiquiatria de setor. Isso, tanto em relação às práticas dos profissionais quanto às políticas públicas, que passam a orientar os serviços de saúde mental a terem uma atuação diversa do higienismo até então prevalente.
"Eu creio que temos que buscar uma clínica diferente. Alguns falam de uma clínica do sujeito. Eu falo de um artesanato da clínica do sujeito, eu creio que é uma clínica de escuta, de acompanhamento também do real material do paciente....é uma clínica cujo objetivo final é a produção de sentido"

Saraceno 
A partir daí, a reforma psiquiátrica no Brasil pode ser entendida como "... um processo que surge mais concreta e, principalmente, a partir da conjuntura da redemocratização, em fins da década de 70 . Tem como fundamentos não apenas uma crítica conjuntural ao subsistema nacional de saúde mental, mas também - e principalmente - uma crítica estrutural ao saber e às instituições psiquiátricas clássicas, dentro de toda a movimentação políticosocial que caracteriza a conjuntura de redemocratização" (Amarante, idem, p. 87). Podemos destacar três momentos na trajetória da reforma psiquiátrica brasileira a partir daí.

\section{"... um processo que surge mais concreta e, principalmente, a partir da conjuntura da redemocratização, em fins da década de 70. Tem como fundamentos não apenas uma crítica conjuntural ao subsistema nacional de saúde mental, mas também - principalmente - uma crítica estrutural ao saber e às instituições psiquiátricas clássicas, dentro de toda a movimentação político-social que caracteriza a conjuntura de redemocratização"}

Amarante

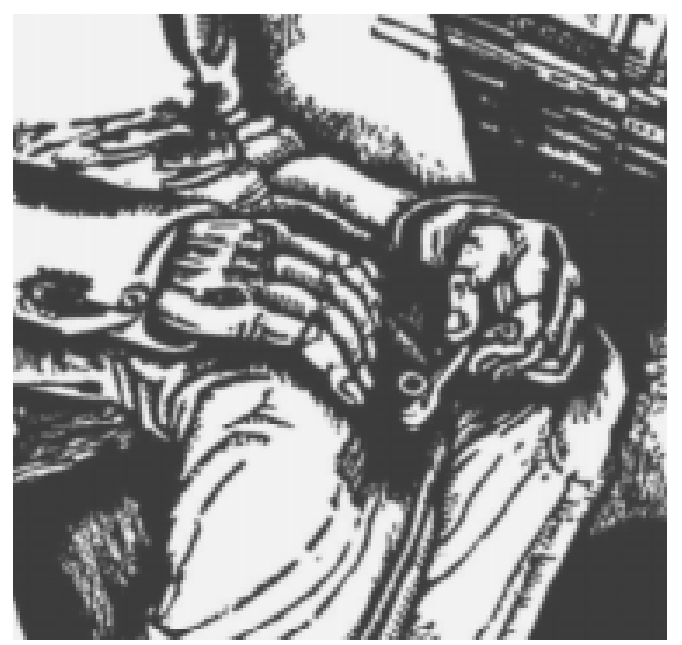

Um primeiro momento, que Amarante (1998) chama de trajetória alternativa, decorre do contexto dos últimos anos do regime militar autocrático, quando se tem o fim do "milagre econômico" e um processo de distensão-abertura democrática. O afrouxamento da censura faz emergir insatisfações e aumentar a participação política dos cidadãos, que passam a questionar a estrutura e a organização do poder, as políticas sociais e econômicas e as condições de vida e trabalho. Surgem as bases para o ressurgimento dos movimentos sociais e partidos políticos e um clamor ao governo de melhoria das condições de vida de toda a população. A partir de 1976, são criados o Movimento de Renovação Médica (REME), o Centro Brasileiro de Estudos de Saúde (CEBES) e o Movimento de Trabalhadores em Saúde Mental (MTSM). Estes tinham como objetivo discutir e organizar a política no setor da saúde e discutir as práticas das categorias profissionais que, por assim dizer, criam as bases para a reforma sanitária e psiquiátrica no Brasil. Esses movimentos sistematizam as primeiras e graves denúncias ao sistema nacional de assistência psiquiátrica, repleto de corrupções, fraudes, violência e tortura, principalmente nos hospitais psiquiátricos. São denunciadas, também, a falta de recursos, a negligência e a tentativa de utilização da Psiquiatria como instrumento de controle social (principalmente através da prática dos ideais da Psiquiatria preventiva comunitária e do higienismo, que continuava existindo). Nessa época, também, começa a surgir um pensamento crítico sobre a natureza e a função social das práticas médicas e psiquiátrico-psicológicas. Chegam até nós os trabalhos de Foucault, Goffman, Bastide, Castel, Basaglia, as experiências da Psiquiatria democrática italiana e outros que colaboram com esses questionamentos.

Um segundo momento da reforma psiquiátrica brasileira pode ser considerado uma trajetória sanitarista. É iniciada nos primeiros anos da década de 80, quando parte considerável do movimento de reforma sanitária, e não só psiquiátrica, passa a ser incorporada como política pública. Por um lado, é uma tática adotada pelo movimento sanitário de ocupação dos espaços públicos de poder e tomada de decisão como forma de introduzir mudanças no campo da saúde. Por outro lado, constitui-se em tática do Estado para absorver o pensamento e o pessoal crítico em seu interior, seja para alcançar legitimidade, seja para reduzir as críticas e denúncias. É um momento fortemente institucionalizante, onde parte das críticas e reflexões do período anterior dão lugar a princípios de que a ciência médica e a administração podem e devem resolver os problemas coletivos. Cresce, então, a importância do saber sobre a administração e o planejamento em saúde - basta colocar em ordem os serviços, os recursos, as instituições, que tudo se resolverá. No campo específico da saúde mental, traduz-se por racionalização, humanização e moralização dos hospitais psiquiátricos e a criação de ambulatórios como alternativa à internação. No entanto, essas mudanças surtiram pouco efeito na atenção dada à saúde mental.

Um terceiro momento, que podemos chamar trajetória de desinstitucionalização, tem início na segunda metade dos anos 80, marcada por eventos importantes como a 8 Conferência Nacional de Saúde (1986), a I Conferência Nacional de Saúde Mental (1987) e o II Congresso Nacional dos Trabalhadores de Saúde Mental (1987). O período tem como ponto mais importante uma ruptura no processo de reforma psiquiátrica, até então restrito às transformações no campo técnico-assistencial, para uma dimensão mais global e complexa: " um processo que ocorre, a um só tempo e articuladamente, nos campos técnico-científico, político-jurídico, teórico-conceitual e sociocultural" (Amarante, idem, p. 76). A I Conferência Nacional de Saúde Mental, realizada logo após a $8^{a}$ Conferência Nacional de Saúde, representa, para a saúde mental, "o fim da trajetória sanitarista de 
transformar apenas o sistema de saúde e o início de uma trajetória de desconstruir, no cotidiano das instituições e da sociedade, as formas arraigadas de lidar com a loucura. É a chamada desinstitucionalização" (Tenório, 2002). Em decorrência dessas idéias, é organizado, pelo MTSM, o II Congresso Nacional dos Trabalhadores de Saúde Mental na cidade de Bauru, interior de São Paulo, que institui o lema "Por uma Sociedade sem Manicômios" e estabelece uma nova proposta de ação para a saúde mental - não apenas as macrorreformas, mas uma preocupação com o ato de saúde, que envolve profissional e cliente; não apenas alterações nas instituições psiquiátricas, mas na cultura, no cotidiano e nas mentalidades. Passam, também, a ser incorporados novos aliados nesse processo, principalmente os usuários dos serviços e seus familiares. É criado, nesse Congresso, o Movimento da Luta Antimanicomial, e instituído o dia 18 de maio como o Dia Nacional da Luta Antimanicomial, visando a articular, em torno dessa causa, parcelas mais amplas da sociedade. A partir dessas reflexões, a questão das estruturas de cuidado ganha outra abordagem. Não se trata mais de aperfeiçoar ou melhorar as estruturas existentes (ambulatórios e hospitais psiquiátricos), mas de inventar novos dispositivos e novas tecnologias de cuidado, exigindo, assim, uma rediscussão da clínica psiquiátrica em suas bases. O objetivo maior passa a ser substituir uma saúde mental centrada no hospital por outra, sustentada em dispositivos diversificados, abertos e de natureza comunitária e territorial, rompendo-se definitivamente com o modelo sanitarista. É nesse momento de intensos debates que começam a se criar serviços de saúde mental que tenham a capacidade de serem substitutivos à internação psiquiátrica, entre eles os CAPS.

\section{O Surgimento dos Centros de Atenção Psicossocial}

O primeiro CAPS do Brasil, denominado Professor Luís da Rocha Cerqueira, surgiu em 1986, na cidade de São Paulo, a partir da utilização do espaço da então extinta Divisão de Ambulatório (instância técnica e administrativa da Coordenadoria de Saúde Mental, responsável pela assistência psiquiátrica extra-hospitalar) da Secretaria Estadual de Saúde. Transformou-se esse local num serviço que se propunha a evitar internações, acolher os egressos dos hospitais psiquiátricos e poder oferecer um atendimento intensivo para portadores de doença mental, dentro da nova filosofia do atendimento em saúde mental desse período.

As inspirações para o CAPS Luís Cerqueira e para os demais que foram criados vieram, em grande parte, das experiências realizadas no exterior, principalmente de alguns princípios das comunidades terapêuticas, da Psiquiatria de setor e da Psiquiatria democrática italiana. A inspiração mais forte, no entanto, segundo Pitta (1994), foi a dos centros de atenção psicossocial de Manágua (Nicarágua), que surgiram em 1986, em plena revolução naquele país. Apesar de todas as dificuldades sociais, econômicas e políticas, esses centros foram maneiras criativas de cuidar, com responsabilidade, de pessoas com problemas psiquiátricos. Utilizavam-se de líderes comunitários, profissionais, materiais improvisados e sucatas para reabilitar as pessoas que, pelos transtornos mentais, eram excluídas da sociedade. As equipes eram interdisciplinares e tinham a proposta de uma ação ligada, ao mesmo tempo, à prevenção, tratamento e reabilitação. Outro aspecto importante desses centros era a parceria com outras instâncias sociais, sendo que alguns deles funcionavam em salões paroquiais ou outros locais. A marca dessas estruturas foi o compromisso ético de que todos têm o direito a uma vida digna a despeito da doença mental ou de outras limitações sociais e econômicas.

Além desses marcos em outros países, houve outras experiências regionais no Brasil, nos anos 80, que também iam ao encontro de uma atuação mais integrada em saúde mental, além de tratar através da inserção do usuário na comunidade e que também inspiraram os CAPS. Entre elas, a "Casa das Palmeiras" no Rio de Janeiro, os núcleos de atenção psicossocial (NAPS) de Santos-SP e outras cidades, os centros de convivência, em São Paulo, a Pensão "Nova Vida", no Rio Grande do Sul, e muitas outras que traziam em si o desejo da reabilitação e a marca da insatisfação quanto ao que era oferecido até então. Estas, ao mesmo tempo, buscavam responsabilizar-se pelos usuários e estabelecer pontes entre eles e a sociedade.

Dessa forma, os CAPS se estruturam como serviços de atendimento diário. Parte-se de um entendimento de que a especificidade clínica de sua clientela, pela sua doença e condições de vida, necessita muito mais do que uma consulta ambulatorial mensal ou semanal. Organizam-se de forma a que o usuário, caso necessite, possa freqüentar o serviço diariamente, e é oferecida uma gama de atividades terapêuticas diversificadas e o acolhimento por uma equipe interdisciplinar. Procura-se oferecer ao usuário a maior heterogeneidade possível, seja nas pessoas com quem possa vincular-se seja nas atividades em que possa engajar-se. Nesses serviços, "o pressuposto é o de que a alienação psicótica implica uma dificuldade específica de expressão subjetiva, refratária, a ser apreendida por instituições massificadas ou pouco aparelhadas para captar e entrar em relação com o singular de cada paciente. 
Do mesmo modo, as dificuldades concretas de vida acarretadas pela doença mental grave devem ser, também elas, objeto das ações de cuidado, incorporando-se à prática psiquiátrica aquilo que tradicionalmente era considerado "extraclínico". O cuidado, em saúde mental, amplia-se no sentido de ser também uma sustentação cotidiana da lida diária do paciente, inclusive nas suas relações sociais" (Tenório, 2002). Os CAPS se constituíram, então, numa ampliação tanto na intensidade dos cuidados aos portadores de transtornos mentais quanto de sua diversidade, incluindo as especificidades de sua clientela e da cidade ou local onde estão inseridos.

\section{A Criação do CAPS Espaço Vivo}

Na cidade de Botucatu, o único hospital psiquiátrico existente é o Hospital Professor Cantídio de Moura Campos (público-estadual), que é referência também para a região. A partir de todo o processo de reforma psiquiátrica, iniciou-se um processo de transformação mais acentuado da assistência prestada aos pacientes desse hospital a partir de 1993. Essa necessidade partiu das orientações das políticas públicas em saúde mental, da diretoria técnica da época e de muitos funcionários. Uma das primeiras e principais mudanças foi a formação de equipes multiprofissionais para o atendimento dos pacientes, até então inexistentes. Foram elaborados pelos funcionários, junto à direção, programas específicos de atendimentos para cada uma das equipes. As equipes criadas foram: dependentes químicos, agudos e moradores. A de dependentes químicos e de agudos (psicóticos e neuróticos graves) atendiam a pacientes em crise que, quando possível, tinham alta e eram encaminhados para continuidade de seu tratamento no nível ambulatorial (ambulatório de saúde mental, centros de saúde etc). A de moradores atendia os pacientes que não possuíam mais família e/ou não possuíam condição de se manter fora da instituição, e, assim, residiam no hospital. Com a criação das equipes e de programas de atendimento específicos, pretendia-se que o encaminhamento para o hospital fosse mais criterioso, evitando reinternações freqüentes, criando maior articulação com os serviços extra-hospitalares de Botucatu e outros municípios, um maior respeito à subjetividade e à liberdade do paciente durante a internação, uma participação e envolvimento da família no tratamento e também criando possibilidades de reinserção social dos pacientes moradores.

Com esses objetivos, conseguiu-se, com o passar do tempo, melhorar o atendimento prestado, diminuir as internações e a sua duração. Mesmo assim, ainda havia uma parte dos pacientes, principalmente do programa de agudos, que não conseguiam adaptar-se ao tratamento prestado no nível ambulatorial e que acabavam, por esse motivo, sendo reinternados freqüentemente. Somava-se a isso a limitação de serviços de atendimento intensivo em saúde mental na cidade e na região, pois só se contava, na época, com o Hospital-Dia da Faculdade de Medicina de Botucatu (que faz parte da Universidade Estadual Paulista - Campus de Botucatu), que prestava esse tipo de atendimento, mas que só tinha condições de atender um número restrito de pacientes.

Começou-se, então, além dos objetivos de se melhorar o atendimento hospitalar, a sentir a necessidade de que o hospital criasse um serviço intensivo extra-hospitalar. Com as modificações ocorridas na instituição e os objetivos alcançados de diminuição das internações e do tempo de permanência, surgiu a proposta da diretoria de aproveitar uma parte dos profissionais para que trabalhassem nesse serviço a ser criado, que se pretendia funcionasse nos moldes de um CAPS para usuários psicóticos e neuróticos graves.

Resolvida a questão de onde viriam os recursos humanos, a outra dificuldade foi quanto ao local para o funcionamento desse serviço. Em contato com a diretoria do Ambulatório de Especialidades do Estado, localizado no centro da cidade de Botucatu, surgiu a possibilidade de ser cedido, para o início do funcionamento do CAPS, o segundo andar daquele prédio, que estava sendo subutilizado.

A seguir, a direção do Hospital Cantídio criou uma comissão, com profissionais experientes em serviços extra-hospitalares, para que selecionasse, entre os funcionários interessados em trabalhar no CAPS, os que mais se adequavam ao perfil exigido para o serviço. Essa comissão selecionou, então, uma médica psiquiatra, três psicólogos, duas assistentes sociais, duas enfermeiras, duas auxiliares de enfermagem e quatro auxiliares de serviço de saúde para comporem a equipe inicial do CAPS.

Como já havia o local e a equipe para o CAPS, os profissionais foram remanejados do hospital e começaram a trabalhar no espaço destinado a esse serviço. Tal fato ocorreu em outubro de 1999. Não se iniciou o atendimento de usuários de imediato, pois havia um consenso da equipe do CAPS e da direção do hospital de que era necessário que se construísse, primeiramente, um projeto terapêutico, enquanto era realizada uma pequena reforma para adaptação do local, contatos com outros serviços e fosse viabilizada toda a parte técnica-administrativa. Além disso, em se tratando de um trabalho que se pretendia interdisciplinar, era fundamental um tempo de 
convivência entre os profissionais, pois, apesar de serem todos funcionários do hospital, muitos não trabalhavam juntos.

A equipe elaborou o projeto do CAPS e tomou as providências necessárias para o início do atendimento. Foram momentos muito ricos, onde todos puderam expor suas opiniões, reflexões, críticas e construir um projeto terapêutico de forma coletiva - onde todas as pessoas e atividades planejadas possuíam o mesmo valor e importância dentro do tratamento que se esperava realizar. Nesses momentos, a equipe pôde respirar, enxergar novos horizontes e ousar... Pôde-se aproveitar as experiências anteriores de cada um, objetivando que o CAPS tivesse um atendimento diferente do que existia na cidade e que fosse singular e individualizado. Os objetivos traçados nesse projeto foram: "1) Atender os usuários portadores de sofrimento mental, evitando ao máximo as internações psiquiátricas; 2) Desenvolver trabalho interdisciplinar que permitisse aos usuários e profissionais potencializarem suas capacidades; 3) Oferecer à clientela uma proposta terapêutica alicerçada no respeito às suas singularidades; 4) Atuar frente à comunidade possibilitando melhorar a compreensão da doença mental, sensibilizando-a para novas práticas de assistência; 5) Integrar-se à rede de serviço de saúde de Botucatu e região atuando como um serviço de referência e contrareferência; 6) Oferecer campo para ensino, pesquisa e aprimoramento profissional" (Projeto Terapêutico do CAPS Espaço Vivo, 1999).

Dessa forma, nas atividades inicialmente programadas para o CAPS, foram levados em conta as preferências pessoais dos funcionários, os talentos que cada um possuía, além da especificidade profissional de cada um. Aquele que tinha afinidade com teatro iria coordenar a oficina de teatro, outra que tinha "talentos" culinários iria coordenar a oficina de culinária, e assim por diante. Foram aproveitadas essas experiências com o intuito de que houvesse prazer e sentido nas atividades, tanto para os usuários quanto para os funcionários.

Após concluído o projeto terapêutico, foi necessária a escolha de um coordenador do CAPS. Antes da escolha, discutiu-se muito sobre o papel desse coordenador, pois a equipe, no projeto, deixou clara a opção por um funcionamento democrático, transparente e igualitário. Sendo assim, o papel do coordenador seria o de uma "ponte" com a direção do hospital (o CAPS é um setor do Hospital Cantídio), um representante perante outros serviços e a comunidade e o centralizador das questões administrativas e burocráticas da unidade, ou seja, toda e qualquer decisão, seja técnica ou administrativa, seria tomada em conjunto e com a participação de toda a equipe. Quando se tratasse de assuntos ligados ao dia a dia do CAPS e às atividades, os usuários participariam da discussão com a equipe através da assembléia do CAPS, que ocorreria semanalmente. Após essas reflexões, foram escolhidos, através de eleição pelos funcionários, o coordenador e um coordenador substituto, para um prazo de tempo determinado pela equipe.

Assim, a equipe do CAPS tinha por meta constituirse numa equipe interdisciplinar. A imagem mais emblemática dessa opção foi a mesa da sala da equipe. Quando do início da montagem do CAPS, foi necessária uma mesa para a sala, a ser utilizada nas reuniões e no contato diário entre os funcionários dos dois períodos de atendimento.

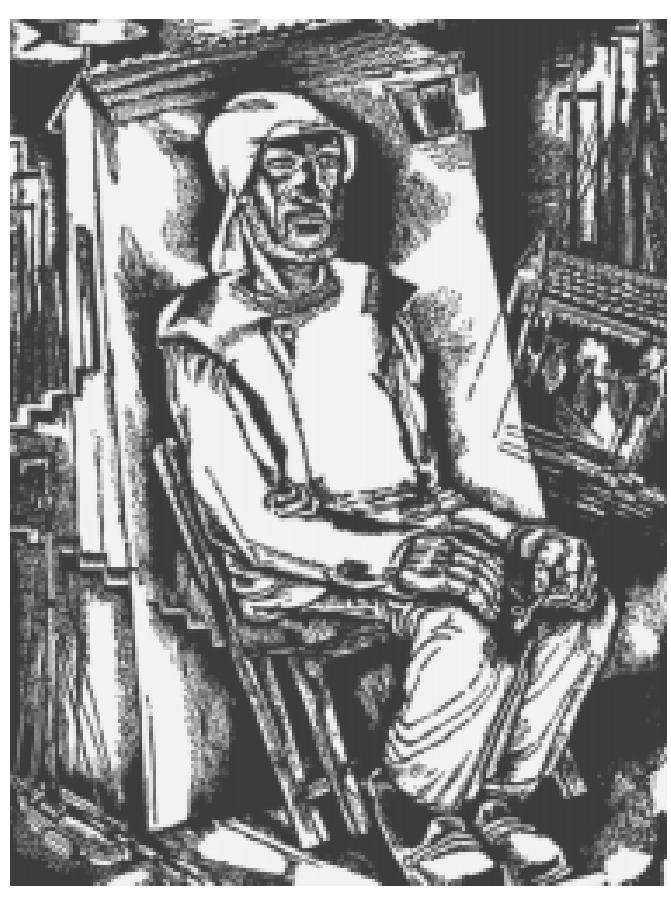

Para esse fim, eis que foi encontrada uma mesa redonda... Tal mesa foi o símbolo mais forte da equipe que estava iniciando o trabalho, pois significava que todos, naquele espaço, tinham a mesma importância e que as decisões seriam sempre tomadas em conjunto, além de ser um símbolo da integração e de união. Assim, essa mesa redonda poderia representar o espírito da equipe do CAPS.

Após a pequena reforma e a conclusão das providências necessárias, iniciou-se o atendimento aos usuários em março de 2000. Para tanto, foi feita divulgação da proposta de atendimento e do tipo de serviço que iria ser prestado à comunidade, através de entrevistas em rádios e jornais. Também ocorreram reuniões com os representantes dos 
serviços de saúde mental da cidade e região com esses mesmos objetivos. No início, a maior parte dos usuários do CAPS eram de pessoas recémsaídas do Hospital Cantídio, muitas delas já conhecidas dos profissionais.

O CAPS foi inaugurado oficialmente em 22 de setembro de 2000, com representantes do Hospital Cantídio, da Secretaria Estadual de Saúde, Prefeitura Municipal, de autoridades locais e regionais e representantes de serviços de saúde mental da cidade e região. A inauguração contou, também, com a apresentação de uma peça de teatro criada e encenada pelos usuários do CAPS. Nessa oportunidade, o CAPS também oficializou o seu nome, escolhido pelos usuários e funcionários: Centro de Atenção Psicossocial Espaço Vivo.

Até 2002, após mais de dois anos do início de suas atividades, o CAPS atendia por volta de 45 usuários da cidade de Botucatu e da região. Funcionava de segunda a sexta-feira, das 8:00 às 17:00 horas, e achava-se localizado no mesmo local de sua inauguração. Vários usuários já haviam passado pelo atendimento, muitos estavam em atendimento e outros em processo de desligamento e retorno a serviços ambulatoriais não-intensivos.

A avaliação que temos é que o processo posto em ação pela equipe do CAPS e a direção do Hospital Cantídio alcançou êxito: construir um serviço de atendimento intensivo fora da área do hospital, com um trabalho em equipe e com respeito profundo pela subjetividade e singularidade dos usuários e funcionários. Tais ingredientes transformaram o CAPS num Espaço Vivo, pois só a vida pulsando, criando, transformando, pode levar à saúde mental e trazer a alegria, a liberdade, enfim, a vida, em sentido pleno, aos portadores de sofrimento psíquico grave e aos trabalhadores da saúde mental.

A Vida é movimento...

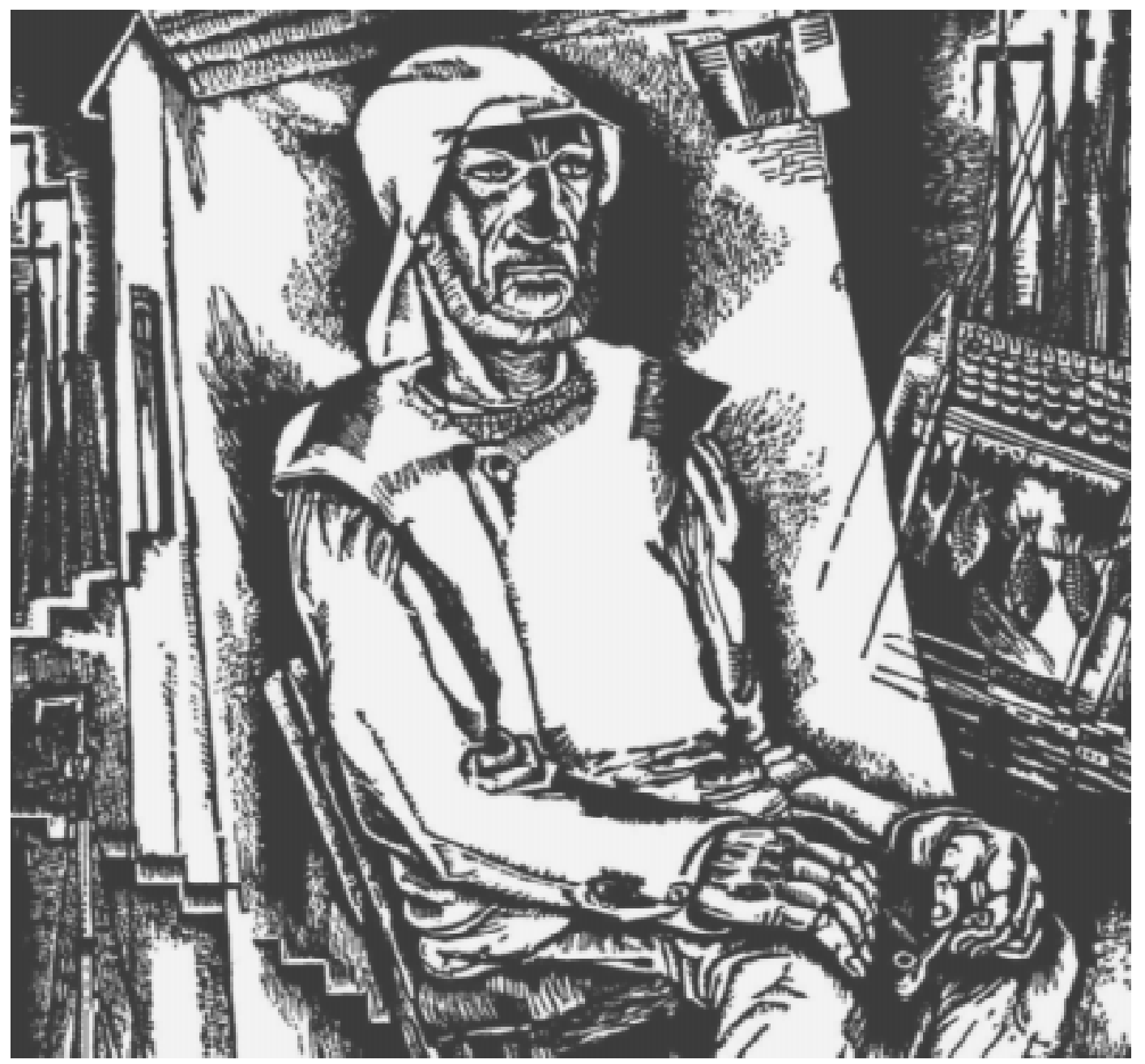


Sérgio Luiz Ribeiro

Rua Moysés Leme da Silva, $n^{\circ} 4-20$, apto. 403 Jardim América

Bauru-SP CEP 17.017-335

Fone: (14) 3227-4558

E-mail: sergio.psi@ig.com.br

Recebido 05/06/03 Aprovado 13/10/04

AMARANTE, Paulo. Loucos pela Vida - a Trajetória da Reforma Psiquiátrica no Brasil. Rio de Janeiro: Fiocruz, 1998.

BIRMAN, Joel. A Psiquiatria Como Discurso da Moralidade. Rio de Janeiro: Graal, 1978

Centro de Atenção Psicossocial Espaço Vivo. Projeto Terapêutico. Botucatu, 1999

MACHADO, R. et al. Danação da Norma: Medicina Social e Constituição da Psiquiatria no Brasil. Rio de Janeiro: Graal, 1978.

PITTA, Ana Maria Fernandes. Os Centros de Atenção Psicossocial: Espaços de Reabilitação? Jornal Brasileiro de Psiquiatria, vol. 43, $n^{\circ} 12$. Rio de Janeiro, 1994, pp. 647-648.
RESENDE, Heitor. Política de Saúde Mental no Brasil: uma Visão Histórica. In Costa, Nilson do Rosário. Cidadania e Loucura - Políticas de Saúde Mental no Brasil. Petrópolis: Vozes, 1987.

SARACENO, Benedetto. As Concepções de Reabilitação Psicossocial Como Referencial Para as Intervençốes Terapêuticas em Saúde Mental. Revista de Terapia Ocupacional da Universidade de São Paulo, vol. 9, nº1. São Paulo, 1998, pp. 26-31.

TENÓRIO, Fernando . A Reforma Psiquiátrica Brasileira, da Década de 1980 aos Dias Atuais: História e Conceitos. História, Ciências, SaúdeManguinhos. Rio de Janeiro, vol. 9(1) , jan. - abr., 2002, pp. 25-29.

YASUI, Silvio. CAPS: Aprendendo a Perguntar. In Lancetti, Antônio (org). Saúde e Loucura 1. São Paulo: Hucitec, 1989, pp. 47 a 59. 